American Journal of Economics and Business Administration 4 (1): 5-12, 2012

ISSN $1945-5488$

(C) 2012 Science Publications

\title{
Service-Learning in a Managerial Accounting Course: Developing the 'Soft' Skills
}

\author{
Victoria Calvert and Rafik Kurji \\ Bissett School of Business, Mount Royal University, \\ 4825 Mount Royal Gate SW, Calgary, Alberta, T3E 6K6, Canada
}

\begin{abstract}
Problem statement: This study explores the impact of a service-learning project embedded in a managerial accounting course through the lens of students' technical, professional and personal development. Academic institutions and Business Schools in particular, are often criticized for producing graduates who are technically capable but lack the capability for teamwork, effective workplace communication and the ability to react effectively in unstructured and complex situations. Further, the perception of business professionals as being capitalists at the exclusion of community engagement is widespread. The authors propose the Service-Learning methodology be adopted as an effective manner in which to not only develop the communication and relationship skills of accounting students, but also to heighten their awareness and affiliation for community service and professional practice. Approach: The process undertaken to successfully launch a project employing the service-learning platform is explained, with emphasis placed upon overcoming operational barriers. The Students in Free Enterprise (SIFE), a student organization, who served a key role by sourcing entrepreneurs in the early stages of venture startup, are also discussed. Results: Results of a successful Service-Learning project in a managerial accounting course is examined within the broader context of students developing skills pertaining to professional practice, citizenship, project management and successful business interaction. Critical learning moments, which entailed students gathering data from entrepreneurs for financial forecasting, contributed to the development of 'soft' skills such as enhanced communication with teammates and clients and the ability to work in an unstructured environment which required confidentiality and client management. Conclusion: This study describes how SL projects integrated into a managerial accounting course addresses some of the graduate competencies required by accounting associations and the broader community, including 'soft' skills, professional practice and citizenship behavior. Suggestions for structuring and managing SL projects in accounting courses may guide faculty in the successful adopting of the methodology.
\end{abstract}

Key words: Service-learning, venture launch, communication skills, professional practice

\section{INTRODUCTION}

The ongoing societal perception of the propensity for business schools to graduate technically competent professionals who lack a moral compass has instigated a critical review of curriculum and teaching andragogy (Diamond, 2005). Public pressure and legislative initiatives to ensure transparency in accounting reporting and auditing have also pressured public accounting associations to articulate the desirability of community-oriented graduates who can articulate moral reasoning and who will demonstrate social responsibility (Frank et al., 2010). The American Accounting Association has indicated that ethical judgment and reflective practice is required due to the reliance of clients upon the ethical behavior of professionals, such as accountants, in an increasing complex environment (Winston and Bahnaman, 2008; Frank et al., 2010). The quandary of teaching business ethics in curriculum that is typically content driven has created a challenge for accounting educators.

Further, while critical thinking and ethical reasoning are deemed core competencies, accounting practitioners and accounting faculty have articulated that written and oral communication are crucial skills for successful practitioners (Sharifi et al., 2009). Jackson (2009) provided an excellent summary of the skills gaps in modern graduates employing international data. The study addressed the need to profile competencies and identified the complexity of assessing multifaceted skill sets such as communication, critical thinking, team-working, meta-cognition and creativity. Key findings highlighted the importance of applied skills as well as critical thinking. Oral and written communication skills were consistently ranked as some of the most important in graduates and further noted as suffering Corresponding Author: Victoria Calvert, Bissett School of Business, Mount Royal University, 4825 Mount Royal Gate SW, Calgary, Alberta, T3E 6K6, Canada Tel: 4034407015 
from wide gaps in required versus actual capability (Jackson, 2009). Stakeholders, such as large accounting firms, stress the complexity of services necessitates the ability to gather information and to analyze and present findings in written and verbal presentations to clientele.

The value of Service-Learning (SL) as an effective methodology has been verified (KenworthyU'Ren, 2008) and the adoption of the practice has provided the experiences necessary to enhance students' communication skills while developing ethical reasoning and technical abilities (Godfrey et $a l .$, 2005). While SL has been incorporated in both undergraduate and graduate business education, the level of adoption in fields such as marketing and management has been much greater than finance and accounting (Andrews, 2007). Impediments to SL in accounting curriculum have been attributed to the perception of accounting faculty that curriculum should focus on content that reflects the national accounting examinations (Rose et al., 2005).

This study describes a SL project that was successfully integrated into a managerial accounting course. The role of SIFE (Students in Free Enterprise) in sourcing entrepreneurs for the project will be highlighted. SIFE is a non-profit student organization that works with business leaders to mobilize university students to make a difference in their communities while developing the social awareness and leadership skills. The development by students of technical and 'soft' skills and the challenges for both students and faculty will also be examined. Finally, processes that would contribute to the successful adoption of the SL andragogy by accounting professors, or other faculty, will be discussed.

Service-learning research:An overview of servicelearning: The foundation for SL was provided by Dewy's 'primacy of experience', which advocated active learning and reflection by students applying academic models to solve problems outside the classroom (Dewy, 1960). Govekar and Rishi (2007) contributed to the literature by defining the key differential between SL and experiential learning as the dual nature of the interaction: benefit is derived by both the students providing a service and the beneficiary. SL is primarily linked with sustaining community based nonprofit organizations while maximizing the educational experience through internships and volunteerism. However, researchers and academics engaged in developing entrepreneurs have engaged in a range of SL practices, some examples of which include students assisting new entrepreneurs to prepare business plans, or providing service to Small and Medium Enterprises (SME) through consulting projects (Calvert, 2009; Calvert et al., 2011a).
The SL platform is comprised of four components: a hands-on learning opportunity, the requirement for reflection, a community-based service which fosters civic values and a beneficial experience both for the student and the community organization (Godfrey and Grasso, 2000). A review of SL practice conducted by Beatty (2010) determined that three models, with different assumptions regarding the purpose of SL, are prominent in SL andragogy. The professional model focuses on career training and the development of cognitive abilities, the civic engagement model is driven by developing engaged citizens and the social change model creates opportunities for empowerment and social justice. While the professional model is most commonly employed as a teaching methodology, the civic and social change models provide the historic grounding for the SL movement (Beatty, 2010).

The SL methodology is flexible and encompasses a plethora of teaching options ranging from volunteer placements lasting only a few hours to semester-long consulting projects. The SL activity may be performed individually or in groups; may be mandatory or optional; and could be embedded in the course content or offered as an extra-curricular exercise, or activity (Godfrey et al., 2005). Godfrey et al. (2005) argue that longer term projects that have been carefully embeeded into course curriculum offer the most significant learning opportunity.

The growing body of literature provides clear evidence for SL as an effective teaching process both for cognitive, technical and skill development (Rama et al., 2000). Govekar and Rishi have reported an enhanced ability to respond to change, better teamwork, an increased awareness of diversity and improved critical and creative thinking for students who were involved in SL projects (Govekar and Rishi, 2007). The SL experience is perceived by students to contribute to their portfolio for employers and to the development of their professional practice (Barr, 2010).

The SL literature has been greatly enriched in recent years by the contributions to the assessment and practice by a range of adopters. For example, a recent article by (Larson and Drexler, 2010) describes a SL assignment for a project management course which was designed to promote the hands-on learning for both technical and interpersonal development. Students engaged with clients in the design and implementation of events for non-profit organizations, including the preparation of planning documentation. The authors, who had previously employed traditional in-class methodologies, observed the SL project to be a powerful learning experience. Whereas in previous years students developed a plan that remained an academic exercise, in the modified course students learned how to apply project management tools to manage real-world circumstances. The structure provided through project proposals, an implementation plan, status reports and 
a post-project audit facilitated a systematic approach to risk management for both the students and the community organizations (Larson and Dexter, 2010).

Business education has been widely criticized for generating graduates with shallow moral values who employ a 'tool-box' mentality for resolving problems (Hsu and Hamilton, 2008). Addressing real-world issues through unstructured experiences, such as those provided by SL, contributes to enhanced skills and cognitive ability as well as to greater ethical understanding and sense of citizenship (Godfrey et al., 2005). Janasz and Whiting (2009) argue that traditional skill-set-focused curriculum is inadequate and that teaching pedagogy must be modified to enable students to adapt quickly within a moral framework. They further suggest that the complex and unanticipated global change necessitates the adoption of a holistic approach to management education where adaptability, moral behavior and global awareness are emphasized and that SL provides pedagogy that facilitates a holistic learning experience. Certainly these attributes would address the call by accounting associations, practitioners and clientele for a broader skill set for accounting graduates.

Accounting courses employing the service-learning platform: An extensive review of SL practices indicated business fields such as marketing and management frequently employ the SL andragogy, whereas the field of accounting and finance rarely adopt SL practices (Andrews, 2007). In addition, the majority of accounting SL applications entail extracurricular activities, however very few are embedded into the curriculum and pertain to a course outcome (Andrews, 2007). The limited adoption of SL in accounting programs has been attributed to two factors: faculty are reluctant to experiment with teaching methods when course outcomes are tied to national exams and accounting curricula does not include the broader outcomes of SL, such as ethical reasoning and community engagement in learning outcomes (Andrews, 2007).

The small but growing body of accounting literature pertaining to SL reflects two formats: extracurricular SL activities pertaining to tax preparation and projects embedded in managerial accounting courses. The tax preparation projects are popular partially because of the perceived limited class time available for individual or team SL projects.

Price and Smith (2008) suggest that a Volunteer Income Tax Assistance Program (VITA) based SL program is meaningful for accounting students as they benefit not only from enhanced practice of online tax submissions, but also through the confidence building derived from the certification they receive as part of the training process. They argue that the most successful delivery model for VITA SL programming is a third-party sponsorship, as faculty have limited time to structure the learning experience (Price and
Smith, 2008). The VITA program provides free-tax preparation for almost two million taxpayers in the United States annually, primarily by partnering with higher education institutions and community organizations. The programs are valuable for accounting students who gain practical working knowledge of their field (Ahrens et al., 2011; Hulsart, 2007). The widespread recognition by both academic institutions and employers of the VITA program contributes to the increasing adoption of the SL practice.

A study Calvert, Kurji and Kurji examines a less sustainable SL tax preparations practice. A sevenyear extracurricular tax return program conducted at a Canadian university was gratifying to the faculty due to the personal growth and increased technical capability of participating students. However, managing the program was time-consuming and administratively cumbersome and operational issues ultimately rendered managing the program untenable (Calvert et al., 2011b). The authors provided insight into the role of not only faculty, but also stakeholders. They suggested that Canadian Accounting Associations have not articulated the need for SL, or identified specific performance outcomes and while accounting firms have indicated they want ethical employees, most have not demanded volunteer service on graduate resumes and that high grades are deemed most critical to the hiring experience. Until the stakeholders convey that SL experiences are critical to the selection process, faculty and business schools in Canada may be reluctant to adopt the practice.

Gujarathi and McQuade (2002) were early adopters of SL, incorporating a project into their intermediate accounting course. Their results indicated that five steps were necessary for a successful service-learning platform: developing institutional and individual conviction for the value of community service, developing alliances with the community agencies, establishing the pedagogical legitimacy of service-learning, motivating the faculty and students about the benefits of service-learning and selecting appropriate assignments.

Chiang (2008) provides insight into the emerging face of accounting education through his discussion of integrating a SL project into an undergraduate management accounting course. His students indicated that while the workload was perceived to be heavy, they appreciated the opportunity to assist a real organization and apply accounting principles. Chiang supports the greater adoption of the SL platform in higher level accounting courses and provides a list of potential services students may offer the community agencies, including: developing and implementing a costing system; preparing a budget and standard costing; developing financial reporting; and identifying general issues and financial analysis. $\mathrm{He}$ indicates that while managing the SL was timeconsuming, many issues could be addressed by proper planning. 
Zamora (2009) responds to the call by (Andrews, 2007; Rama et al., 2000) to enhance the relevance of managerial accounting through SL by engaging her students in a social enterprise project. The SL platform provided a rich learning opportunity for students who examined the tradeoff between opportunities for enhance profitability versus social programming and operating missions, providing an opportunity for both the application of accounting skills and complex business ethics analysis. Students indicated in a post-project survey that they perceived the project to be an interesting and informative experience and those they had contributed in a meaningful way.

Accounting curricula has been under pressure to develop better competency in the three skills ranked by practitioners and accounting faculty: analytical thinking, written communication and oral communication (Albrecht and Sack, 2000). A competency based accounting communication course that incorporates SL methodology offers an effective prototype for the development of 'soft' skills ((Sharifi et al., 2009). The graduate course requires public service activities, multiple oral and written communication exercises and requires individual response to feedback from both teammates and the client, contributing to enhanced awareness and communication capability.

In a recent article examining the SL platform within the context of a Canadian extracurricular tax preparation course, the authors concluded that greater impact of desired learning outcomes could be achieved by embedding a SL project in a higher level accounting course (Calvert et al., 2011b). This study describes a pilot SL project in a managerial accounting course. The authors postulated that the teaching strategy would focus upon the development of professional and analytical skills for accounting professionals using the professional SL model and would also provide an opportunity for the broader social awareness agenda typical of the civic SL model as defined by (Beatty, 2010).

\section{MATERIALS AND METHODS}

One of the primary barriers to the adoption by faculty of the SL andragogy entails the securing and management of community organizations that will fit the SL project (Kenworthy-U'Ren, 2008; Calvert et al., 2011a; Chiang, 2008). Contacting, screening and managing the nature of the project to ensure learning parameters are met reduce operational issues during the student interaction with community clients, but also to the richness of the learning opportunity (Chiang, 2008).

A project launched in August 2010 by the Mount Royal University (MRU) chapter of SIFE, a student organization, provided the key community linkages necessary to pilot the SL project for a managerial accounting course for the fall 2010 term. The 'Master the Blueprint' program offered by SIFE entailed a twelve-week program to facilitate the development of business plans for local female entrepreneurs. SIFE organized weekly speakers who highlight components, such as marketing or finance, necessary to develop a plan. The entrepreneurs would work with SIFE members to develop their business plan and in most cases, seek financing (Refer to Appendix A for details regarding the project).

Victoria Calvert, one of the authors, was one of the speakers for the series and a working relationship between Rafik Kurji, who teaches managerial accounting and the SIFE team, was constructed with the intent of assisting the entrepreneurs in preparing budgets while engaging students in community service. The accounting techniques introduced in the managerial accounting course were perceived by the authors to fit the needs of the participating entrepreneurs, as financial planning and costing was not part of their skill set, but comprised a critical component of business planning. While the SIFE program served as a liaison between the accounting faculty and the entrepreneur, it is suggested that community organizations could be substituted for the entrepreneurs and that many nonprofit organizations require assistance in financial forecasting.

The format of the SIFE program was conducive to an academic SL project, as the entrepreneurs attended a weekly session on Saturday mornings during the term, allowing on-campus scheduling for student teams. The entrepreneurs represented a wide range of ventures, including:

- Freelance Direct Response Copywriting and Consultancy.

- Corporate writing, writing and editing for promotional materials.

- Consulting in home organization areas such as wardrobes and kitchens.

- Alternative Dental services.

- Fabric High Chair Manufacturing.

- Manufacturing of stainless steel water bottles.

Nine entrepreneurs were enrolled in the SIFE program; however, only six were actively engaged throughout the twelve-week session and available for the SL project.

Student preparation and the project: The Managerial Accounting course at MRU is attended by second year-students enrolled in a BBA program, most of whom have only one introductory accounting course. For many of the students, engaging in an SL project would be a new and challenging experience. 
Although business ethics would have been introduced in some courses, the requirements for maintaining the professional standards for a client relationship would not have been addressed. Further, the team-work nature of the project and the real-world impact of the their engagement, where new entrepreneurs would be relying upon them to assist in preparing plans for financial presentations to bankers and funders, created an sense of reality not encountered in prior text-book based curriculum. Consequently, the skills embodied in the project were much broader than typically encountered in an accounting course and required the instructor to introduce material to enhance both technical proficiencies and the development of softer skills such as team communication, management of the client relationship and professional ethics.

The project was introduced six weeks into the term, allowing for coverage of master budget preparation and financial preformed theory. Students were advised of the project process, as well as some of the challenges they may encounter, such as the ambiguous nature of the data and the need for project logistics and team management. The requirement for confidentiality regarding client information, as well as the management of the client relationship, was highlighted. Debriefing the student experience was to be covered during class time and was incorporated to a limited extend into the course curriculum. Students signed a confidentiality agreement, reinforcing the real-world nature of the project as well as the professional implications of the project.

The SL project was based upon the budgeting exercise completed in the managerial accounting classes employing the traditional case-based format and was allocated the same worth of $10 \%$ of final grades. Rather than the case employed by other sections, the SL project required active student engagement for data collection, client communication and the application of course concepts by developing assumptions for budget and forecasting. The students were advised that the start-up nature of the project could create a challenge, as financial statements from previous years would not be available for students to reference. However, the contribution students could provide was highlighted, as their services would directly contribute to the enhanced probability of their client creating a viable plan and thereby securing finances during the start-up phase. Additional exposure to industry experts was provided when students attended training workshops with their clients which covered a range of topics including marketing research, marketing strategy, banking relationships and methods for securing financing.

Managing the service-learning process: Students became familiar with the course content prior to the SL project, which did not begin until the 8th week of class. Students we introduced to managerial concepts such as forecasting, the application of variable and fixed costing, margin analysis and the controllability factor of costing at varied activity levels through exercises and cases from the text. They became familiar with budget preparation and understood the principles for sales budgeting, cash collection, direct materials and labor budgets, as well as the types of information necessary for managerial decisions through class exercises. The judgment and capability to deal with unstructured data and the ability to develop appropriate assumptions for budget preparation was provided through the SL project. Working with the entrepreneurs provided an excellent exposure to unstructured material, where the students were required to gather and interpret the data and create logical assumptions through discussions with the client.

Students were informed of the assignment details and requested to form groups of four; the instructor did not engage in team selection. Project management processes described by the instructor facilitated a smooth team environment, with limited problems. Individual teams exchanged contact information and developed schedules, with specific dates identified for weekly meetings and a project timeline.

The students and entrepreneurs attended a workshop facilitated by two professional accountants, with input from the instructor, in which fundamental accounting concepts surrounding financial statements and performance measurement of financial statements by ratio analysis was discussed. Teams met with their entrepreneur client to review the venture, any financial data available and to request additional information. This client-accountant exchange followed the format used by accounting professionals in order to "Know Your Client" (KYC). Students made follow-up calls to discuss operational aspects with the client.

\section{RESULTS}

Overall the SL project proved to be an effective teaching process, with students growing through the experience and the entrepreneur 'clients' benefiting from the assistance with budgets and financial forecasting for their business plans. During a debriefing session at the end of term, students indicated their preference for the SL method rather than the canned cases employed in other accounting classes. Surprisingly, there was limited complaining by students regarding the extra workload, with many expressing the value of the activity and pride in their ability to contribute to the success of a new venture. A flavor of the student's perception of the project is provided by the following student statements submitted to the instructor: 
- 'The assignment was very interesting and helpful for building accounting skills'

- 'The assignment involved work not only in the area of accounting but also other areas of business. It was a great way to introduce what is involved in the preparation of a master budget'

- 'The project was a good taste of what is really involved in the business world'

- 'It seems like one needs more than just basic numbers to be able to prepare budgets'

- 'The project is a great idea to make you apply business concepts in a real life situation'

- It was initially a very frustrating experience, but as we gained confidence in our approach, our information and our assumptions, we realized the value of this project'

- It made me think on how to complete a budget when information is not always available. I was able to find ways to get that information'

- 'I was hoping to apply more management accounting topic coverage such as process costing, absorption costing, variable costing, cost of goods manufactured, work in process. in our assignment. Our company was not involved in manufacturing activities'

Reflection by the students and the instructor identified critical learning moments that provided value beyond the opportunity to apply managerial accounting concepts. The students were forced to adapt to an unstructured situation when working with their entrepreneurs. Communication was not always timely and the data when provided was basic, as the ventures were in the start-up phase and prior financial statements were not available. The students gained a deeper understanding of financial inter-relationships and the impact of assumptions. Equally significant, the students developed their communication skills when working with the client and their teammates under a stressful and time-restricted situation. The personal commitment of their client provided students with an insight as to their professional role and the impact of accounting professionals on client operations and the success of their business. The knowledge that the forecasting and budgeting service provided by the teams would contribute to the securing of funds for venture created a real impact on the students. Each of the clients finished the SIFE program with a business plan, of which the financial forecasting and budgeting was prepared by the managerial accounting students. A further benefit for the entrepreneurs was the training they received from the students and the budget preparation was interactive, with the students explaining the process and logic. This greater understanding by the entrepreneurs of financial statements, as well as budgeting process, may facilitate operational efficiencies and increate the viability of the ventures.

The self management of the project provided multiple challenges and caused great concern to numerous students. The lack of data, uncertainty as to the methodology for assumptions, managing the client relationship, as well as self-doubt as to their ability to apply managerial accounting concepts, created learning moments. The gradual acceptance by students of the fluid nature of the project and the encouragement by the instructor to address the issues calmly and logically resulted in expressions of confidence and competence by end of the SL experience.

The increased capability of students to perform managerial accounting exercises was demonstrated. Of equal significance was the personal growth, the increased awareness of the role of professional accountants, the greater understanding of client relationship management and the demonstration of enhanced communications skills. Essentially the process required students to use their judgment and assume an active role as investigators, rather than the passive role which is typical in text-based learning environments.

\section{DISCUSSION}

The insights provided by Chiang (2008) and Zamora (2009) regarding the structuring of the SL platform in a managerial accounting course were helpful when constructing the SL experience. The pilot project provided a dynamic learning opportunity for the instructor and the class methodology will be adapted prior to further adoption of the project. Key issues and suggested resolutions, regarding the SL project for new ventures are as follows:

- Securing clients that fit course learning requirements: While the SIFE program facilitated the on- campus access of clients for students, the type of clients were not a good fit for managerial accounting. Many of the ventures were services and as such several costing techniques were not applicable. Further, the ventures were in the start-up phase and the lack of any financial data caused students to generate assumptions to a greater extent than had been anticipated. Finally, the decline in clients from nine organizations to six caused a quick revamping of the team structure. As the time required to source and screen potential project clients would not be feasible, the authors will seek community organizations that serve entrepreneurs to secure both greater numbers of clients and ventures that provide a better fit for managerial accounting curriculum

- Team Guidance: The time allocated for debriefing in class was not adequate. While approximately one hour had been estimated for 
individual team and instructor consultation, the learning challenges required extensive additional office hours, with some teams requiring up to three hours of guidance. The provision of project management tools, such as PERT or GANTT charts are anticipated to reduce team conflict and confusion. Further, an additional hour will be allocated for in-class coverage when introducing the project to discuss the barriers and successful and unsuccessful actions of teams during the pilot project

- Awareness of student capabilities: The instructor was surprised by the lack of prior exposure of most students to projects which required both analytical reasoning and integrative capability. Student lack of understanding of financial relationships become apparent when students queried the impact of their forecasting assumptions. Consequently the curriculum is being modified to include exercises addressing these topics. The instructor also confirmed students have the capability to grow and succeed in an unstructured and fluid real world application of accounting

- Teaching satisfaction: While conducting the pilot SL project presented some operational and time challenges the author found the experience exciting. His students grew in their role as accounting professionals and the concrete assistance provided to the entrepreneurs was of real value. The exercise confirmed the author's belief that teaching renewal is both desirable and possible by incorporating SL andragogy into business curriculum

In summary, the authors view the inclusion of a SL project in the managerial accounting course to have contributed to the learning process in a manner not possible through the case or exercise methodologies. Students demonstrated their understanding of managerial accounting concepts, as well as the softer skills and professional behavior required for accounting graduates. The students and the entrepreneurs both benefited from the process.

\section{CONCLUSION}

This study describes how SL project integrated into a managerial accounting course addresses some of the graduate competencies required by accounting associations and the broader community. The development by students of technical and 'soft' skills such as oral and written communication, as well as ethical behavior has emerged in recent years as a required learning outcome. The SL platform, implemented under the professional model, has proven to be a successful methodology for developing not only technical capability, but personal and professional development. The implementation of a SL project in which student teams prepared financial forecasting for entrepreneurs in the start-up phase of the venture verified the effectiveness of the SL methodology.

The role of SIFE provided a helpful role in sourcing entrepreneurs for the project. However, it is noted that accounting faculty could secure clients for a financial planning SL exercise through many organizations, including the local Chamber of Commerce. Students demonstrated both their technical proficiency and enhanced professional skills through their management of the client relationship and project deliverables. Learning moments were provided by numerous 'crisis' situations, primarily caused by the unstructured nature of the data and the subsequent problem resolution. Students expressed satisfaction with the experience and a true sense of accomplishment by assisting a real organization in the start-up phase of their venture.

While the insights regarding the successful structure of a managerial accounting course SL project were helpful, the author encountered several challenges. Suggestions to enhance the teaching process include: introducing project management tools such as PERT or GANTT charts to facilitate team management, increasing the class time for individual team meetings with the instructor and modifying the curriculum to facilitate the conceal capability of students regarding financial relationships and the implications of assumptions. The authors recommend the adoption of SL andragogy by faculty to enhance student analytical reasoning, 'softer' skills such as communication, as well as professional ethics and practice.

\section{REFERENCES}

Ahrens, M., S. Counte and D. Hasband, 2011. Successful service learning projects in accounting and business curriculums. Community College National Center for Community Engaement.

Albrecht, W.S. and R.J. Sack, 2000. Accounting Education: Charting the Course Through a Perilous Future. 1st Edn., American Accounting Association, ISBN: 0865390886, pp: 72.

Andrews, C.P., 2007. Service learning: Applications and research in business. J. Educ. Bus., 83: 19-26.

Barr, J., 2010. The service-learning experience in a capstone marketing course: A framework for assessing student outcomes. Int. J. Strategic Manage.

Beatty, J.E., 2010. For which future? Exploring the implicit futures of service-learning. Int. J. Organ. Anal., 18: 181-197. DOI: $10.1108 / 19348831011046254$ 
Calvert, V., 2009. Enhancing small business performance through service learning. Ind. J. Econ. Bus.

Calvert, V., K. Jagoda and L. Jensen, 2011a. Developing social entrepreneurs through business curriculum: A Canadian experience. Ind. J. Innovat. Learn., 10: 215-225. DOI: 10.1504/IJIL.2011.042077

Calvert, V., R. Kurji and S. Kurji, 2011b. Service learning for accounting students: What is the faculty role? Proc. ASBBS, 17: 791-801.

Chiang, B., 2008. Integrating a service-learning project into management accounting coursework-A sharing of implementation experience and lessons learned. Accoun. Educ., 17: 431-445.

Dewy, J., 1960. How We Think: A Restatement of the Relation of Reflective Thinking to the Educative Process. 1st Edn., Heath, Lexington, MA., pp: 301.

Diamond, M., 2005. Accounting education, research and practice: After enron, where do we go? Eur. Accoun. Rev., 14: 353-362. DOI: 10.1080/09638180500124855

Frank, G., E. Ofobike and S. Gradisher, 2010. Teaching business ethics: A quandary for accounting educators. J. Educ. Bus., 85: 132-138.

Godfrey, P.C. and E.T. Grasso, 2000. Working for the Common Good: Concepts and Models for Service-Learning in Management. 1st Edn., American Association for Higher Education, Washington, DC., ISBN: 1563770210, pp; 200.

Godfrey, P.C., L.M. Illes G.R. Berry, 2005. Creating breadth in business education through servicelearning. Acad. Manage. Learn. Educ., 4: 309323.

Govekar, M.A. and M. Rishi, 2007. Service learning: Bringing real-world education into the b-school classroom. J Educ. Bus., 83: 3-10.

Gujarathi, M.R. and R.J. McQuade, 2002. Servicelearning in business schools: A case study in an intermediate accounting course. J. Educ. Bus., 77: 144-150. DOI: 10.1080/08832320209599063

Hsu, J. and K. Hamilton, 2008. Meeting the needs of adult learners and non-traditional students: The effective application of adult learner principles and techniques to an undergraduate business programme. Int. J. Innovat. Learn., 5: 394-412. DOI: $10.1504 /$ IJIL.2008.017560
Hulsart, R.W., 2007. Small numbers, large returns: College students helping community members prepare income tax returns. College Teach., 48: 48-50.

Jackson, D., 2009. An international profile of industry-relevant competencies and skill gaps in modern graduates. Int. J. Manage. Educ., 8: 2957.

Janasz, D.S.C. and V.R. Whiting, 2009. Using service to transform learning: Re-scripted $\mathrm{ABCs}$ for our changing environment. Int. J. Organ. Anal., 17: 60-75. DOI: $10.1108 / 19348830910948904$

Kenworthy-U'Ren, A., 2008. A decade of servicelearning: A review of the field ten years after JOBE's seminal special issue. J. Bus. Ethics, 81: 811-822.

Larson, E. and J.A. Drexler Jr., 2010. Project management in real time: A service-learning project. J. Manage. Educ., 34: 551-573. DOI: 10.1177/1052562909335860

Price, D.W. and D.L. Smith, 2008. Income tax service learning opportunities: A look at alternative models. Global Perspectives Account. Educ., 5: 43-53.

Rama, D.V., S.P. Ravenscroft, S.K. Wolcott and E. Zlotkowski, 2000. Service-learning outcomes: Guidelines for educators and researchers. Issues Accoun. Educ., 15: 657-692.

Rose, J.M., A.M. Rose and C.S. Norman, 2005. A service-learning course in accounting information systems. J. Inform. Syst., 19: 145172.

Sharifi, M., G.B. McCombs, L.L. Fraser and R.K. McCabe, 2009. Structuring a Competency-based accounting communication course at the graduate level. Bus. Commun. Q., 72: 177-199. DOI: $10.1177 / 1080569909334052$

Winston, M.D. and S. Bahnaman, 2008. Preparation for ethical decision-making: An analysis of research in professional education. Library Inform. Sci. Res., 30: 222-230. DOI: 10.1016/j.lisr.2008.02.007

Zamora, V., 2009. Using a social enterprise project in a management accounting course. 